\title{
A Study on Public Adoption of Robo-Taxis in China
}

\author{
Mingyu Liu $\mathbb{D}^{1},{ }^{1}$ Jianping Wu $\mathbb{D},{ }^{1}$ Chunli Zhu, ${ }^{1}$ and Kezhen $\mathrm{Hu} \mathbb{D}^{2}$ \\ ${ }^{1}$ Department of Civil Engineering, Tsinghua University, Beijing 100084, China \\ ${ }^{2}$ China Academy of Information and Communication Technology, Beijing 100191, China \\ Correspondence should be addressed to Jianping Wu; jianpingwu@tsinghua.edu.cn
}

Received 19 May 2020; Revised 6 August 2020; Accepted 23 September 2020; Published 7 October 2020

Academic Editor: Eneko Osaba

Copyright (C) 2020 Mingyu Liu et al. This is an open access article distributed under the Creative Commons Attribution License, which permits unrestricted use, distribution, and reproduction in any medium, provided the original work is properly cited.

Autonomous vehicles (AVs) have been reported to improve road safety, reduce traffic congestion, and increase urban mobility. However, the high price of AVs is currently a challenge for most consumers. Robo-taxi services, with ride-sharing services and AVs, are regarded as a good approach to solving this problem. As some companies have started testing Robo-taxis on the actual road, it has become important to investigate public adoption of Robo-taxi services before they are more widely introduced to the market. This study aims to explain and predict users' acceptance of Robo-taxis by extending the Technology Acceptance Model by including the construct of social influence. Data were collected from an online survey in China and analyzed using linear regression models. The results indicate that perceived usefulness, perceived ease of use, and social influence have significant positive correlations with people's behavior intentions to use Robo-taxis. Perceived ease of use further has an indirect effect on intention to use via perceived usefulness. The results of this study can serve as good references for policymakers, operators, and future transport researchers.

\section{Introduction}

Various developments in vehicle automation technology have been made in recent years, including automatic braking, automatic cruise control, intelligent speed assistance, and lane-keeping assist systems [1]. The technology of autonomous vehicles (AVs) has the potential to ensure roadway safety by reducing the number of traffic crashes caused by human error [2]. Further, AVs also have the potential to reduce traffic congestion, increase mobility, and reduce fuel consumption [3]. In fact, many companies have made efforts in the development of AVs, such as Delphi (supplier), Daimler (manufacturer), and Google (technology firm) [4].

Despite the potential benefits of AVs, high cost presents a considerable challenge to increasing their use, with an additional charge of up to USD 50,000 per vehicle [5]. Therefore, some studies have proposed combining AV technology (Society of Automotive Engineers [SAE] Level 4 or 5) with ride-sharing and taxi services to gain popularity, which are known as Robo-taxis, Robo-cabs, self-driving taxi services, or driverless taxi services [6, 7]. These services would be able to provide on-demand mobility and last-mile travel solutions for users at a low price [8]. Moreover, Robotaxis, a type of shared autonomous vehicles (SAVs), could reduce parking issues and private car ownership levels significantly [9]. People can also save money on the costs of vehicle maintenance, repair, and insurance if they choose Robo-taxi services.

Many companies worldwide have made efforts to develop Robo-taxi technology. Google provided 1 billion USD in financing to Lyft in 2017 to support Waymo's Robo-taxi strategy [10]. Additionally, in 2018, Aptiv and Lyft tested Robo-taxis during the International Consumer Electronics Show in Las Vegas, Nevada [11]. On June 21, 2019, Apollo Robo-taxi, supported by the company Baidu, received 45 licenses from the Changsha government, in the Hunan Province of China [12], and in August 2019, these Robo-taxis were put into use in a specific area of Changsha city with a 50 kilometer roadway [13]. People can book and pay for a Robo-taxi on the Internet, similar to current e-hailing services. In fact, many studies have been proposed to explore the benefits and barriers of Robo-taxis or SAVs. Some studies focused on the relocation strategies of SAVs, and 
findings indicated that one SAV can replace between 3 and 11 conventional vehicles $[14,15]$. Moreover, SAVs can reduce parking demand by up to $90 \%$ [16] and can reduce trip costs by up to $85 \%$, due to the higher utilization of vehicles [9]. However, in the implementation of Robo-taxi services, several barriers were identified, such as technological barriers (fully automated vehicles not yet on the road), regulatory barriers (vehicle-licensing standards), and cost (with affordability being a key issue) [9].

A previous study showed that one of the biggest roadblocks for mass adoption of AVs is not a technical factor, but a psychological one [17]. Currently, most studies about AV acceptance have been conducted in developed countries, with few relevant studies in China. A study conducted in Australia, the United States, and the United Kingdom investigating public opinion about autonomous and self-driving vehicles showed that most participants were interested in AVs, but were not willing to pay extra money for this service [18]. Further, a Chinese study showed that after participants had direct experience with AVs with SAE level 3, they reported being more willing to use AVs [3]. High safety levels, convenience of use, and even gender have been found to influence acceptance of AVs [19-21].

To the best of the authors' knowledge, this is the first study to investigate people's adoption of Robo-taxis in China from a psychological perspective. This study aimed to investigate consumers' acceptance of Robo-taxis before the advent of this service in China. The Technical Acceptance Model (TAM) has been previously applied to understand consumers' acceptance of car navigation technology [22], AVs [1], and autonomous electric vehicles (AEVs) [23]. As it has been noted that others' attitudes toward new technology will affect people's choices [24], this study extended the typical TAM with a new factor named "social influence" (SI).

This paper is organized as follows: a literature review is presented in Section 2; Section 3 describes the survey's methodology, including the proposed hypotheses, survey approach, participants, and measurement design; Section 4 reports detailed survey results, related discussion, and limitations; and Section 5 concludes the paper and provides practical implications and suggestions.

\section{Literature Review}

TAM, revised from the Theory of Reasoned Action, is one of the most successful theories for explaining how the public accepts and establishes opinions concerning a specific technology [22]. The basic TAM includes three constructs: perceived usefulness (PU), perceived ease of use (PEU), and public acceptance [25]. PU is defined as to what degree an individual believes that using a certain technology will enhance his or her job performance. Perceived ease of use (PEU) is defined as to what degree an individual believes that using a particular technology will be effortless. Public acceptance has been defined in various ways for different study purposes, involving different aspects such as willingness to use and sum of attitudes [26]. Researchers generally select a single aspect of acceptance to study [3].
Several models have been proposed to investigate users' acceptance on information technology, including TAM [25], Unified Theory of Acceptance and Use of Technology (UTAUT) [27], and UTAUT2 [28]. Among these models, TAM has been validated by many researchers to explain people's intentions to use specific services [29, 30] and technologies related to AVs $[3,31]$. Furthermore, TAM has demonstrated relatively high performance in explaining driver acceptance of new in-vehicle technologies [32]. Given the success of TAM in predicting public attitudes and acceptance of AVs, we chose TAM as a base model to explain public attitudes toward and adoption of Robo-taxis.

Many researchers have validated TAM for different disciplines. Studies have shown that PU and PEU can have a significant effect on public adoption of technology $[1,23,25]$. Moreover, PEU has been proven to affect individual behavior intention (BI) via casual pathways [23]. Thus, a product's ease of use has an indirect effect on public acceptance. In addition to these two basic constructs, many researchers have extended TAM with specific factors to investigate public acceptance of new vehicle-related technologies. For example, the construct of environmental concern (public awareness of environmental problems) was introduced in TAM to investigate public acceptance on AEVs [23]. Choi and Ji validated the importance of trust (people's beliefs regarding automation) on consumers' adoption of AVs by extending the typical TAM [33]. In another study, the constructs of trust and perceived safety, defined as "a climate in which drivers and passengers can feel relaxed, safe and comfortable, while driving," were added to investigate public adoption of self-driving vehicles, along with PU and PEU. These four constructs were found to be good predictors of user acceptance, especially after participants had an AV experience [3].

\section{Approach}

\subsection{Model and Hypotheses}

3.1.1. Perceived Usefulness. Perceived usefulness was described as the degree to which a user believes that using Robo-taxis will enhance his or her job performance. PU is one of the basic constructs in the typical TAM [1, 22]. Previous studies have shown PU to be a fundamental determinant of user acceptance $[1,23,25]$. When users think the specific technology is useful, they may complete more work with the same amount of effort and improve work performance. Therefore, in this study, we first proposed the following hypothesis $(\mathrm{H})$ :

$\mathrm{H} 1$. PU is positively related to $\mathrm{BI}$ toward Robo-taxis.

3.1.2. Perceived Ease of Use. Perceived ease of use indicates the degree to which a user believes the use of Robo-taxis will be free of effort, which is another fundamental factor in the typical TAM framework $[1,22]$. In addition to PU, PEU has been shown to be an important factor for predicting users' acceptance on specific technologies directly $[1,23,25]$. Moreover, in some studies, PEU has been shown to have a 
direct positive effect on PU $[1,29]$. However, PEU sometimes does not have a significant effect on BI [34]. Therefore, the importance of PEU to users' acceptance on Robo-taxis is not as straightforward as TAM suggests. It is essential to examine the following hypotheses:

H2. PEU is positively related to BI toward Robo-taxis.

H3. PEU is positively related to PU toward Robo-taxis.

3.1.3. Social Influence. Although the basic TAM has been shown to be valid in predicting user acceptance of information technology, these fundamental constructs cannot fully explain the impact of technological and usage-context factors that may alter consumer acceptance $[1,30]$. Therefore, an extended TAM was proposed in the present study, with a new predictor variable, SI. SI indicates the degree to which an individual perceives that important others believe he or she should use a particular technology [1] (e.g., Robotaxis in this study). A previous study reported that approximately half of the respondents (51\%) would prefer their family, friends, and neighbors to use AVs prior to their adoption [24]. The reason is that consumers may gain confidence in the technology and experience social pressure after it is adopted by their friends and neighbors, suggesting SI can positively influence BI to use AVs. Therefore, we hypothesized the following:

H4. SI is positively related to BI toward Robo-taxis.

Figure 1 depicts the research model based on prior hypotheses, which demonstrates that PU and SI can influence BI directly, and PEU can affect BI directly and indirectly.

3.2. The Survey. This survey was conducted via one of the largest Chinese online survey platforms, Wenjuanxing (https://www.wjx.cn/). A link was disseminated through social networks and the Wenjuanxing platform itself. Respondents from different age groups, education levels, and income groups were included in the sample. The survey was conducted in two phases: a pilot study and a full web-based questionnaire. First, the questionnaire was pilot-tested with eight individuals randomly selected through social networks. Based on feedback from the pilot study, the questionnaire was refined, and a revised final online questionnaire was developed. To control survey quality, a rule was set that people with the same IP address and username could access the link only once. Additionally, if the answer time was less than 5 minutes, the questionnaire was considered invalid. Moreover, several attention-check questions were included in the survey to identify whether a respondent was answering the survey carelessly. To make sure respondents had a good understanding of Robo-taxis, a text-based (in Chinese) introduction to Robo-taxis was shown at the beginning of the questionnaire. All survey questions were presented in Chinese. A total of 1,495 questionnaires were received, and 454 were validated to be satisfied.

Respondents' demographic information is presented in Table 1 . Of the respondents, $54.6 \%$ were men and $46.4 \%$

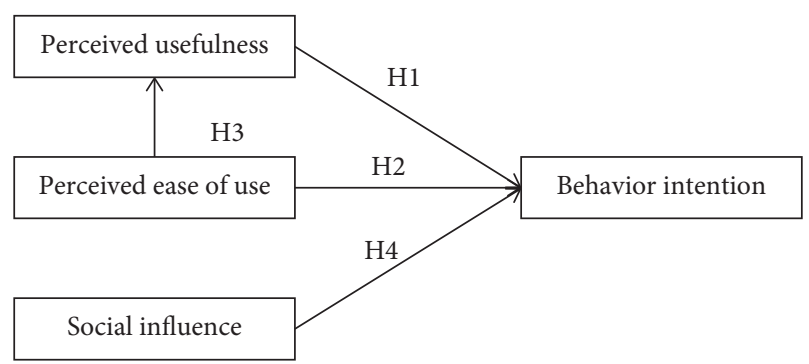

Figure 1: Extended TAM.

TABLE 1: Respondents' demographic information.

\begin{tabular}{lcc}
\hline Response variable & Options & Percentage (\%) \\
\hline \multirow{2}{*}{ Gender } & Male & 54.6 \\
& Female & 46.4 \\
\hline \multirow{4}{*}{ Age } & $18-24$ & 21.1 \\
& $25-34$ & 54.8 \\
& $35-44$ & 17.8 \\
Education & $>45$ & 6.2 \\
\hline \multirow{4}{*}{ Annual income } & Master's degree or above & 10.4 \\
(yuan) & Bachelor's degree & 83.9 \\
& High school or below & 5.7 \\
\hline & None (e.g., students) & 6.8 \\
& Less than 40,000 & 9.3 \\
& 40,000-100,000 & 35.7 \\
& $100,000-200,000$ & 37.2 \\
& More than 200,000 & 11.0 \\
\hline
\end{tabular}

were women. Respondents' ages ranged from 18 to $64: 21.1 \%$ were in the 18-24 age group, $54.8 \%$ were in the $25-34$ age group, $17.8 \%$ were in the $35-44$ age group, and $6.2 \%$ were over 45 years old. Most participants $(94.3 \%)$ had a bachelor's degree or higher. Among the respondents, $16.1 \%$ had a personal annual income less than 40,000 yuan, $35.7 \%$ between 40,000 and $100,000,37.2 \%$ between 100,000 and 200,000 , and $11.0 \%$ over 200,000 .

3.3. The Questionnaire and Measurements. We designed a Robo-taxi acceptance investigation questionnaire in Chinese, modified from previous research $[1,23]$, concerned with AVs, and developed some new items for the questionnaire (PU4 and PU5). A 12-item modified measurement scale was implemented to assess BI to use Robo-taxis. On the questionnaire, the construct of PU contained 5 items, the construct of PEU contained 3 items, and the constructs of SI and BI contained 2 items each, which are shown in Table 2. A five-point Likert scale was used to rate the items of each construct on the questionnaire. For the constructs of PU, PEU, and SI, 1 represents "strongly disagree" and 5 represents "strongly agree," and for the construct of BI, 1 represents "extremely unlikely" and 5 represents "extremely likely."

\section{Results and Discussion}

4.1. Dimensionality of the Scales and Results. A reliability test has been developed to analyze the degree of consistency among the items in each construct by calculating Cronbach's 
TABLE 2: Construct measurements.

\begin{tabular}{|c|c|c|}
\hline Constructs & Items & Literature \\
\hline Perceived usefulness (PU) & $\begin{array}{l}\text { PU1: I think Robo-taxis would be useful in meeting my transportation needs } \\
\text { PU2: I think the use of Robo-taxis would make me feel safer (than normal vehicles) } \\
\text { PU3: I think the use of Robo-taxis would decrease accidents } \\
\text { PU4: I think there should be some entertainment equipment in Robo-taxis, such as smart } \\
\text { cinema } \\
\text { PU5: I think it would be interesting to use Robo-taxis }\end{array}$ & Modified from [1] \\
\hline $\begin{array}{l}\text { Perceived ease of use } \\
\text { (PEU) }\end{array}$ & $\begin{array}{l}\text { PEU1: I think it would be easy to learn to operate Robo-taxis } \\
\text { PEU2: My interactions with Robo-taxis would be clear and easy to understand } \\
\text { PEU3: I think it would be easy for me to use Robo-taxis to go anywhere I wanted }\end{array}$ & $\begin{array}{l}\text { Modified from } \\
{[23]}\end{array}$ \\
\hline Social influence (SI) & $\begin{array}{l}\text { SI1: I would be proud if people saw me using a Robo-taxi } \\
\text { SI2: People whose opinions I value would like to use Robo-taxis }\end{array}$ & Modified from [1] \\
\hline Behavior intention (BI) & $\begin{array}{l}\text { BI1: Assuming AEVs come into use, I intend to use them } \\
\text { BI2: Assuming AEVs come into use, I intend to recommend them to others }\end{array}$ & $\begin{array}{l}\text { Modified from } \\
{[23]}\end{array}$ \\
\hline
\end{tabular}

alpha in SPSS. Table 3 shows the results of the reliability test and Cronbach's alpha. Each of the factors achieved acceptable internal reliability (measured using Cronbach's alpha)_PU $(\alpha=0.75)$, PEU $(\alpha=0.72)$, SI $(\alpha=0.71)$, and BI ( $\alpha=0.70)$ - which met the general rule of thumb of 0.40 $[35,36]$. The means and standard deviations are shown in Table 3. The mean item scores for the four constructs were higher than the midpoints of their respective scales. This indicated that respondents were generally optimistic about PU and PEU for Robo-taxis. Moreover, positive SI was reported regarding Robo-taxi use. High scores for the construct of $\mathrm{BI}$ indicated that respondents were very likely to use Robo-taxis in the future.

Regarding the questions about PU of Robo-taxis, as shown in Figure 2, most respondents strongly or somewhat agreed that Robo-taxis would be useful in meeting their transportation needs (82\%). Furthermore, $81 \%$ of respondents indicated that using Robo-taxis would be interesting, and $74 \%$ wanted some entertainment equipment to relax, such as smart cinema. However, only $45 \%$ of participants agreed that Robo-taxis would decrease accidents, while $46 \%$ thought Robo-taxis were safer than normal vehicles. Therefore, before the advent of Robo-taxis, safety systems, including security protection and data privacy, should be enhanced to increase public interest in using this service.

Additionally, regarding the questions about PEU of Robo-taxis, as shown in Figure 3, 79\% of respondents agreed with the statements "I think it would be easy to learn to operate Robo-taxis" and "My interactions with Robo-taxis would be clear and easy to understand." Furthermore, 65\% thought they could easily use Robo-taxis to go anywhere they wanted.

Moreover, as shown in Figure 4, over half of the respondents thought they would feel proud if other people saw them using a Robo-taxi (57\%). Additionally, almost $74 \%$ of the respondents strongly or somewhat agreed with the statement "People whose opinions I value would like to use Robo-taxis."

Finally, regarding public adoption of Robo-taxis, $83 \%$ of respondents reported to be likely or extremely likely to use
Robo-taxis once they are available. Furthermore, $71 \%$ would like to recommend this service to other people, as shown in Figure 5.

4.2. Data Analysis and Hypothesis Testing. To validate the hypotheses proposed in Section 2, we developed two multiple linear regression models using standardized coefficients. Hypothesis testing results are shown in Figure 6 and Table 4. The first multiple linear regression model was used to analyze the relationship between PU, PEU, SI, and BI to use Robo-taxis, and the second was between PEU and PU. The results showed that $\mathrm{PU}$ had a positive effect on $\mathrm{BI}$ $(\beta=0.332, p<0.001)$ and that PEU also had a positive effect on BI $(\beta=0.232, p<0.001)$. Furthermore, SI also had a positive effect on BI $(\beta=0.325, p<0.001)$. Therefore, $\mathrm{H} 1$, $\mathrm{H} 2$, and $\mathrm{H} 3$ were supported. PU, PEU, and SI accounted for $58.7 \%$ of the variance in $\mathrm{BI}\left(R^{2}=58.7 \%, p<0.001\right)$. Moreover, PEU had a positive effect on PU; thus, H4 was supported. PEU managed to explain $39.2 \%$ of the variance in PU $\left(R^{2}=39.2 \%, p<0.001\right)$.

4.3. Discussion. This study used a self-report questionnaire to examine consumers' intention to use Robo-taxis. Based on an extended TAM, the results of this study indicated that PU, PEU, and SI have a significant effect on people's BI to use Robo-taxis in the future. Moreover, PEU was positively correlated with PU, and the four proposed hypotheses were supported by the data.

The results showed that PU, which can be regarded as perceived benefits, had a significant positive effect on people's intention to use Robo-taxis, and this effect was stronger than for any other factors. This indicated that people who believe Robo-taxis will be useful are more prone to report acceptance of Robo-taxis. Furthermore, some previous studies showed that PU can explain most people's acceptance of a product $[1,3]$, which is in line with the findings of this study. Therefore, to increase consumer acceptance of this service, the benefits of Robo-taxis should be 
TABLE 3: The results of measurements, means, standard deviations, and reliability.

\begin{tabular}{lcccc}
\hline Constructs & Items & Mean & Standard deviation & Cronbach's alpha \\
\hline & PU1 & 3.97 & 0.76 & 0.99 \\
\multirow{2}{*}{ Perceived usefulness (PU) } & PU2 & 3.52 & 0.98 \\
& PU3 & 3.40 & 0.92 \\
& PU4 & 3.85 & 0.87 & 0.75 \\
\multirow{2}{*}{ Perceived ease of use (PEU) } & PU5 & 4.09 & 0.87 & 0.72 \\
& PEU1 & 4.04 & 0.87 & 0.99 \\
\multirow{2}{*}{ Social influence (SI) } & PEU2 & 4.02 & 0.85 & 0.71 \\
\hline \multirow{2}{*}{ Behavior intention (BI) } & PEU3 & 3.78 & 0.88 & 0.90 \\
\hline
\end{tabular}

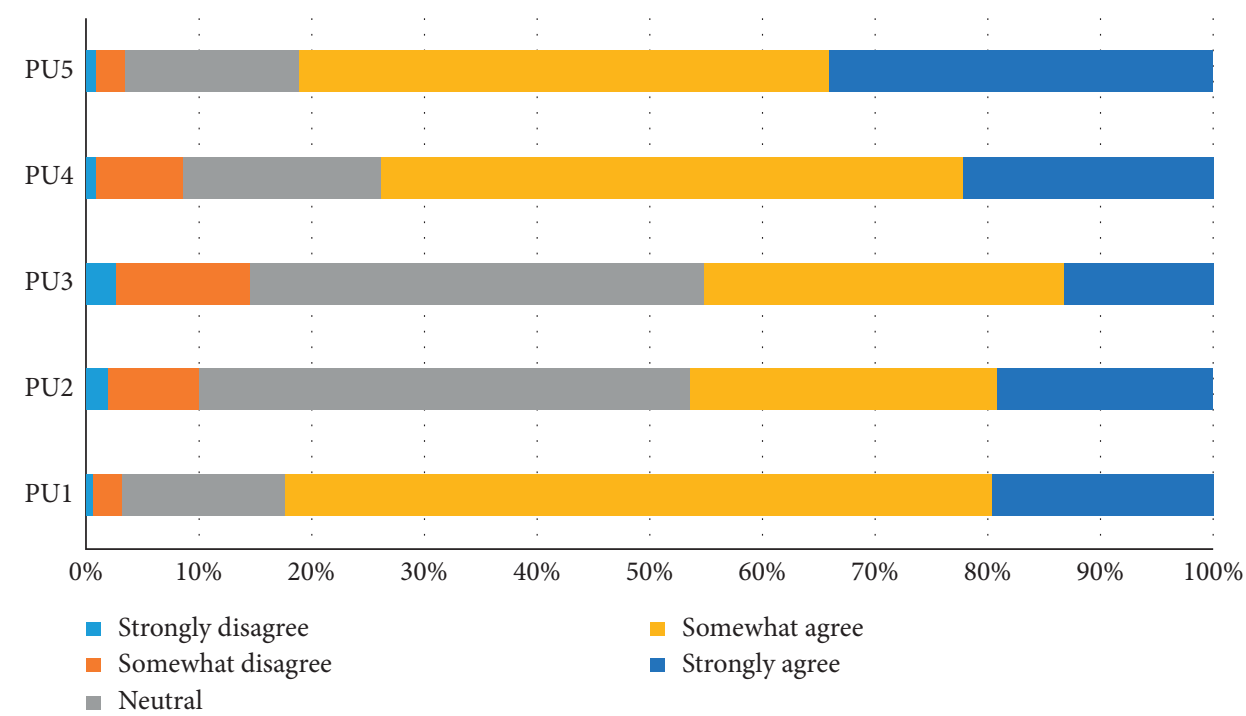

Figure 2: Percentage of perceived usefulness of Robo-taxis.

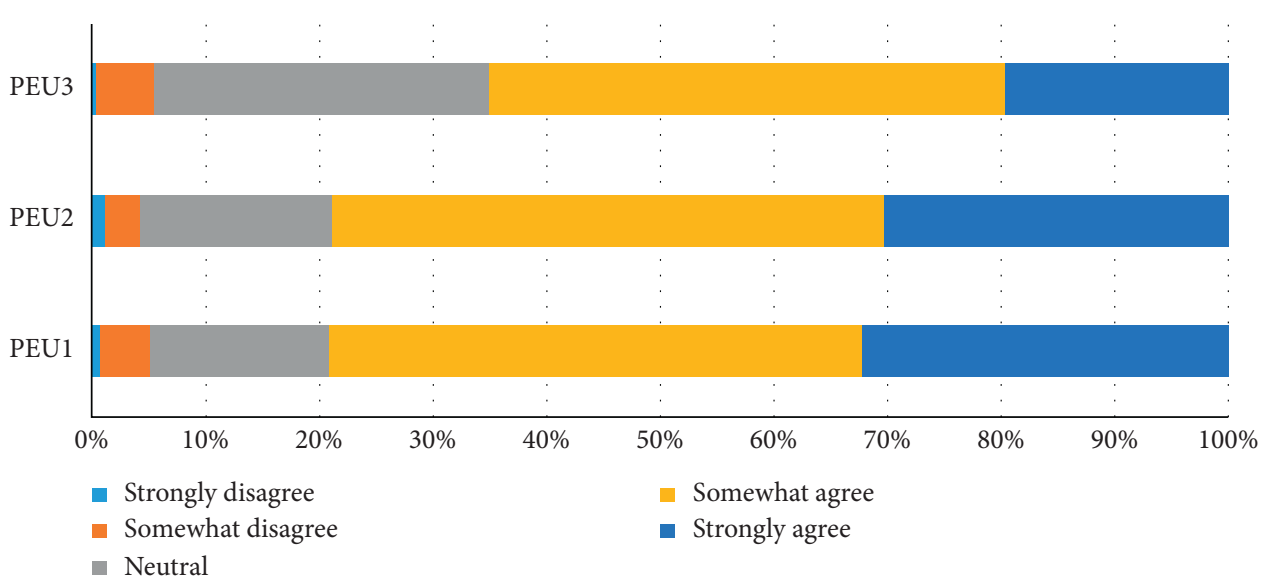

FIgURE 3: Percentage of perceived ease of use of Robo-taxis.

emphasized during their design and promotion, such as no parking, low travel costs, and high safety levels.

Moreover, SI also had a positive effect on public adoption of Robo-taxis. This suggested that if people are supported by others in the use of Robo-taxis, they will be more willing to accept the service when it becomes available on the market. However, an interesting finding in this study was that the beta value of SI (0.325) was just a little lower 


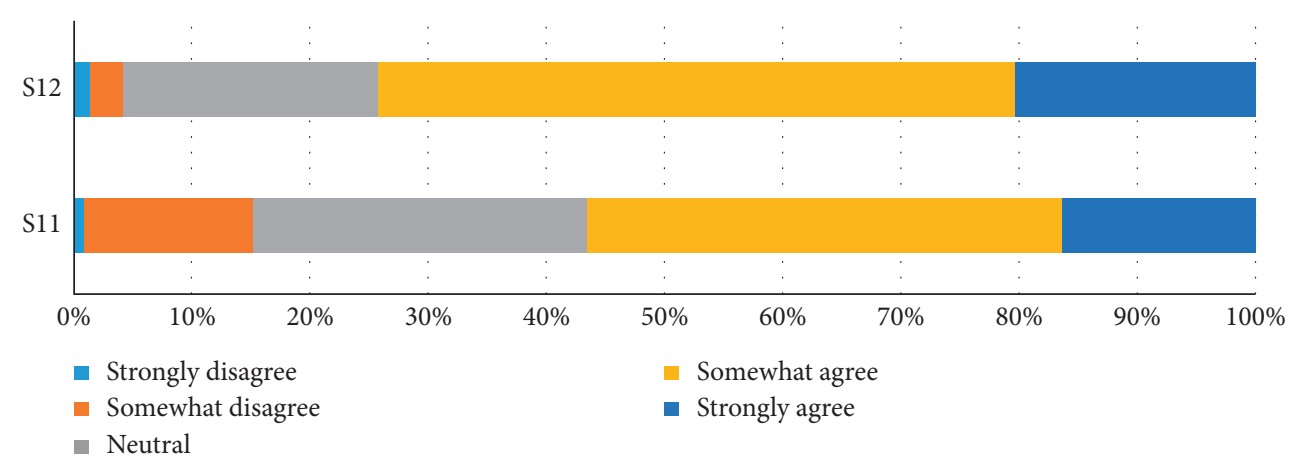

Figure 4: Percentage of social influence on using Robo-taxis.

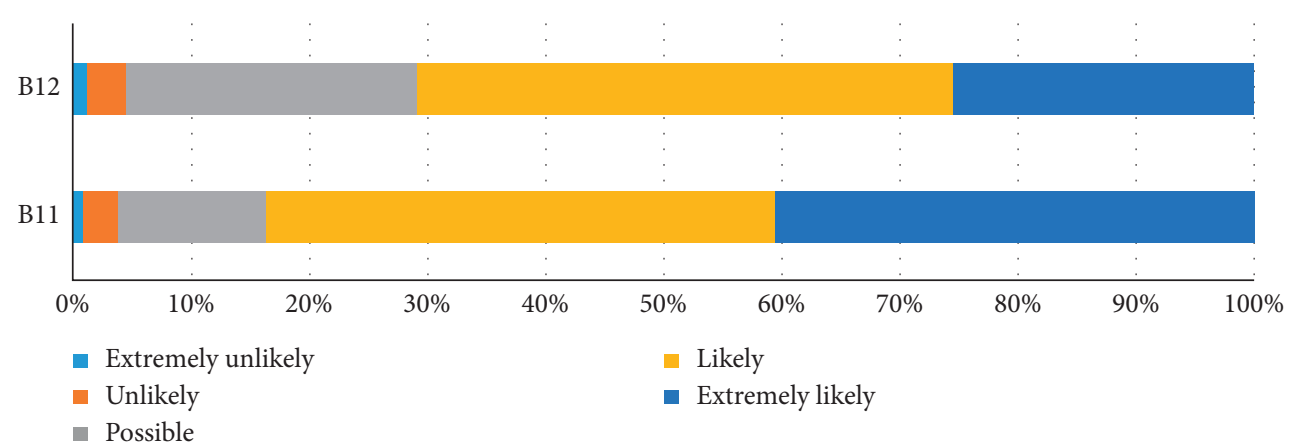

Figure 5: Percentage of behavior intention to use Robo-taxis.

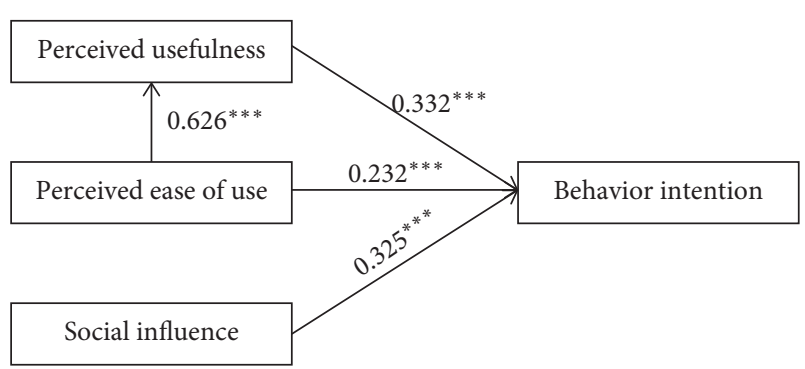

FIgURE 6: Results of the relationships in the research model.

TABLE 4: The results of hypothesis testing.

\begin{tabular}{lcc}
\hline Path & Beta & $\Delta R^{2}$ \\
\hline $\mathrm{H} 1: \mathrm{PU} \longrightarrow$ BI & $0.332^{* * *}$ & $0.468^{* * *}$ \\
$\mathrm{H} 2 \mathrm{PEU} \longrightarrow \mathrm{BI}$ & $0.232^{* * *}$ & $0.060^{* * *}$ \\
$\mathrm{H} 3 \mathrm{SI} \longrightarrow \mathrm{BI}$ & $0.325^{* * *}$ & $0.059^{* * *}$ \\
$\mathrm{H} 4 \mathrm{PEU} \longrightarrow \mathrm{PU}$ & $0.626^{* * *}$ & $0.392^{* * *}$ \\
\hline
\end{tabular}

${ }^{*} p<0.05,{ }^{* *} p<0.01,{ }^{* * *} p<0.001$.

than that of PU (0.332). This indicated that SI is also a very strong factor in Chinese people's acceptance of Robo-taxis. One possible reason for this could be that, in China, people are very likely to be influenced by opinions from others or even society in general [37]. Therefore, policy support from the government and psychological encouragement may be good approaches to promote Robo-taxis acceptance. Policy support from the government represents a trend of development and approval of Robo-taxi services, making people feel confident in this technology. Psychological encouragement, which can include "VIP" services to shorten wait times when people travel with family or friends, can make consumers feel proud to use Robo-taxis.

PEU seemed to have a smaller influence on public attitudes toward the use of Robo-taxis in the present study. This was slightly different from some previous studies, which found that consumers are more influenced by how easy it is to use a product than its usefulness [38]. One possible reason for this finding could be that most participants $(94.3 \%)$ had a bachelor's degree or higher, suggesting it may be feasible for them to learn how to operate a Robo-taxi. Nevertheless, car manufacturers should still focus on convenience in using Robo-taxis. Moreover, PEU also had a positive effect on PU. Thus, people who perceive low costs for Robo-taxis are likely to perceive benefits from this service as well, indicating there is an indirect effect of PEU on public adoption of Robo-taxis via usefulness, which is consistent with previous studies $[23,39]$.

4.4. Limitations. Most respondents in this survey were between the ages of $18-44$ years (93.8\%). This may have caused some bias in the results, which could reduce the generalizability of the findings. However, as Robo-taxis are still being tested, and it will take some time for them to be ready to provide services on actual roads, people aged 18-44 are more likely to be the main group to use this service; therefore, the conclusions of the present study are still meaningful in predicting public adoption of Robo-taxis in the future. The results showed that PU, PEU, and SI only 
explained $58.7 \%$ of the variance in BI. This means that the extended TAM cannot capture all the factors that impact individual BI to use Robo-taxis. Some additional variables may be used to improve predictions of user intention, such as safety, trust in Robo-taxis, and sharing experiences.

\section{Conclusion}

Autonomous technologies have enormous potential to enhance mobility. As the biggest roadblock for mass adoption of Robo-taxis may be psychological, not technological, it is critical to develop a better understanding of consumers' willingness to use Robo-taxis. This study employed an extended TAM to investigate to what degree consumers intend to use Robo-taxis in the future and what the main factors are that influence public acceptance. The survey was conducted online with adults over 18 years of age, and the results showed that PU, PEU, and SI appeared to have a significant effect on BI to use Robotaxis. Moreover, PEU was also shown to have an indirect effect on BI. From the perspective of total effects, PU and SI played bigger roles than PEU in predicting intention to use Robo-taxis.

Based on these findings, some implications can be provided to improve public acceptance of Robo-taxi services before they become available on the market. First, the benefits of Robo-taxis should be emphasized to the public, such as low prices, no worries about parking, reduced traffic congestion, and high efficiency compared with current normal vehicles. Second, raising SI is another effective way to increase adoption of Robotaxi use. Third, psychological encouragement should also be designed for Robo-taxi services. For example, VIP services could be provided to reduce waiting time and make consumers proud to use the service, which is related not only to SI but also to PU. Fourth, safety and security systems for Robo-taxis, including data privacy and security protection, should be carefully designed to attract people who will use this service.

The more the public learns about Robo-taxis, the higher the intentions will be to use the service. Furthermore, some other factors, such as sharing experiences and trusting the safety of Robo-taxis, may potentially have a positive impact on the public's intention to use Robo-taxis and could be considered in future studies. The findings in this study can provide a good foundation for further research and offer useful insight into designing and promoting Robo-taxi services.

\section{Data Availability}

The data generated during the current study are owned by Future Transport Research Center, Tsinghua University, and are not publicly available. Please contact the corresponding author for details.

\section{Conflicts of Interest}

The authors declare that there are no conflicts of interest regarding the publication of this article.

\section{Acknowledgments}

The authors gratefully acknowledge the support provided by the NSFC Zhejiang Joint Fund for the Integration of Industrialization and Informatization (U1709212) and "Research on frontiers of intelligent transport system" funded by China Association for Science and Technology, National Natural Science Foundation of China (U1509205).

\section{References}

[1] I. Panagiotopoulos and G. Dimitrakopoulos, "An empirical investigation on consumers' intentions towards autonomous driving," Transportation Research Part C: Emerging Technologies, vol. 95, pp. 773-784, 2018.

[2] National Highway Traffic Safety Administration, Federal Automated Vehicles Policy: Accelerating the Next Revolution in Roadway safety, US Department of Transportation, Washington, DC, USA, 2016.

[3] Z. Xu, K. Zhang, H. Min, Z. Wang, X. Zhao, and P. Liu, "What drives people to accept automated vehicles? Findings from a field experiment," Transportation Research Part C: Emerging Technologies, vol. 95, pp. 320-334, 2018.

[4] K. Merfeld, M.-P. Wilhelms, S. Henkel, and K. Kreutzer, "Carsharing with shared autonomous vehicles: uncovering drivers, barriers and future developments-a four-stage Delphi study," Technological Forecasting and Social Change, vol. 144, pp. 66-81, 2019.

[5] A. Stocker and S. Shaheen, "Shared automated vehicles: review of business models," in Proceedings of the International Transport Forum Discussion Paper, Ottawa, Canada, July 2017.

[6] D. J. Fagnant, K. M. Kockelman, and P. Bansal, "Operations of shared autonomous vehicle fleet for Austin, Texas, market," Transportation Research Record, vol. 2563, no. 1, pp. 98-106, 2015.

[7] E. Ackerman, "Hail, robo-taxi! [top tech 2017]," IEEE Spectrum, vol. 54, no. 1, pp. 26-29, 2017.

[8] R. Krueger, T. H. Rashidi, and J. M. Rose, "Preferences for shared autonomous vehicles," Transportation Research Part C: Emerging Technologies, vol. 69, pp. 343-355, 2016.

[9] D. J. Fagnant and K. M. Kockelman, "The travel and environmental implications of shared autonomous vehicles, using agent-based model scenarios," Transportation Research Part C: Emerging Technologies, vol. 40, pp. 1-13, 2014.

[10] https://fortune.com/2017/10/19/alphabet-leads-1-billioninvestment-in-lyft/.

[11] https://www.autonews.com/article/20180108/MOBILITY/ 180109792/aptiv-to-continue-testing-Robotaxi-fleet-invegas-long-after-ces.

[12] http://www.sohu.com/a/322970509_782058.

[13] http://auto.sina.com.cn/zz/sh/2019-09-26/detail-iicezueu862 0718.shtml.

[14] T. D. Chen, K. M. Kockelman, and J. P. Hanna, "Operations of a shared, autonomous, electric vehicle fleet: implications of vehicle \& charging infrastructure decisions," Transportation Research Part A: Policy and Practice, vol. 94, pp. 243-254, 2016.

[15] K. Spieser, K. Treleaven, R. Zhang et al., "Toward a systematic approach to the design and evaluation of automated mobilityon-demand systems: a case study in Singapore," Road Vehicle Automation, pp. 229-245, Springer, Berlin, Germany, 2014.

[16] W. Zhang, S. Guhathakurta, J. Fang, and G. Zhang, "Exploring the impact of shared autonomous vehicles on urban parking 
demand: an agent-based simulation approach," Sustainable Cities and Society, vol. 19, pp. 34-45, 2015.

[17] A. Shariff, J.-F. Bonnefon, and I. Rahwan, "Psychological roadblocks to the adoption of self-driving vehicles," Nature Human Behaviour, vol. 1, no. 10, pp. 694-696, 2017.

[18] B. Schoettle and M. Sivak, A Survey of Public Opinion about Autonomous and Self-Driving Vehicles in the US, the UK, and Australia, Transportation Research Institute, University of Michigan, Ann Arbor, MI, USA, 2014.

[19] R. A. Daziano, M. Sarrias, and B. Leard, "Are consumers willing to pay to let cars drive for them? Analyzing response to autonomous vehicles," Transportation Research Part C: Emerging Technologies, vol. 78, pp. 150-164, 2017.

[20] D. Howard and D. Dai, "Public perceptions of self-driving cars: the case of Berkeley, California," in Proceedings of the Transportation Research Board 93rd Annual Meeting, vol. 14, Washington, DC, USA, January 2014.

[21] C. Hohenberger, M. Spörrle, and I. M. Welpe, "How and why do men and women differ in their willingness to use automated cars? The influence of emotions across different age groups," Transportation Research Part A: Policy and Practice, vol. 94, pp. 374-385, 2016.

[22] E. Park, H. Kim, and J. Y. Ohm, "Understanding driver adoption of car navigation systems using the extended technology acceptance model," Behaviour \& Information Technology, vol. 34, no. 7, pp. 741-751, 2015.

[23] J. Wu, H. Liao, J.-W. Wang, and T. Chen, "The role of environmental concern in the public acceptance of autonomous electric vehicles: a survey from China," Transportation Research Part F: Traffic Psychology and Behaviour, vol. 60, pp. 37-46, 2019.

[24] P. Bansal, K. M. Kockelman, and A. Singh, "Assessing public opinions of and interest in new vehicle technologies: an Austin perspective," Transportation Research Part C: Emerging Technologies, vol. 67, pp. 1-14, 2016.

[25] F. D. Davis, "Perceived usefulness, perceived ease of use, and user acceptance of information technology," MIS Quarterly, vol. 13, no. 3, pp. 319-340, 1989.

[26] E. Adell, A. Várhelyi, and L. Nilsson, "The Definition of acceptance and acceptability," Driver Acceptance of New Technology: Theory, Measurement and Optimisation, pp. 1121, Ashgate Publishing Limited, Farnham, UK, 2014.

[27] V. Venkatesh, M. G. Morris, G. B. Davis, and F. D. Davis, "User acceptance of information technology: toward a unified view," MIS Quarterly, vol. 27, no. 3, pp. 425-478, 2003.

[28] V. Venkatesh, J. Y. L. Thong, and X. Xu, "Consumer acceptance and use of information technology: extending the unified theory of acceptance and use of technology," MIS Quarterly, vol. 36, no. 1, pp. 157-178, 2012.

[29] C.-L. Hsu, M.-C. Chen, and Y.-H. Lin, "Information technology adoption for sustainable development: green e-books as an example," Information Technology for Development, vol. 23, no. 2, pp. 261-280, 2017.

[30] R. Fayad and D. Paper, "The technology acceptance model E-commerce extension: a conceptual framework," Procedia Economics and Finance, vol. 26, pp. 1000-1006, 2015.

[31] C. Lee, C. Ward, M. Raue et al., "Age differences in acceptance of self-driving cars: a survey of perceptions and attitudes," in Proceedings of the International Conference on Human Aspects of IT for the Aged Population, pp. 3-13, Springer, Vancouver, Canada, 2017.

[32] M. M. Rahman, M. F. Lesch, W. J. Horrey, and L. Strawderman, "Assessing the utility of TAM, TPB, and
UTAUT for advanced driver assistance systems," Accident Analysis \& Prevention, vol. 108, pp. 361-373, 2017.

[33] J. K. Choi and Y. G. Ji, "Investigating the importance of trust on adopting an autonomous vehicle," International Journal of Human-Computer Interaction, vol. 31, no. 10, pp. 692-702, 2015.

[34] S.-Y. Chen, "Green helpfulness or fun? Influences of green perceived value on the green loyalty of users and non-users of public bikes," Transport Policy, vol. 47, pp. 149-159, 2016.

[35] R. A. Peterson, "A meta-analysis of variance accounted for and factor loadings in exploratory factor analysis," Marketing Letters, vol. 11, no. 3, pp. 261-275, 2000.

[36] S. Nordhoff, J. De Winter, M. Kyriakidis et al., “Acceptance of driverless vehicles: results from a large cross-national questionnaire study," Journal of Advanced Transportation, vol. 2018, 22 pages, Article ID 5382192, 2018.

[37] C. Qi, "The influence of Chinese social action orientation on a translator's culture translation," Journal of Sichuan University of Science \& Engineering (Social Sciences Edition), vol. 27, no. 3, pp. 65-68, 2011.

[38] C.-F. Chen and P.-C. Chen, "Applying the TAM to travelers' usage intentions of GPS devices," Expert Systems with Applications, vol. 38, no. 5, pp. 6217-6221, 2011, in Chinese.

[39] A. J. T. Solbraa Bay, "Innovation adoption in robotics: consumer intentions to use autonomous vehicles," M.S. thesis, Norwegian School of Economics, Bergen, Norway, 2016. 